\title{
Current situation of the presence of the zoonotic nematode Dirofilaria immitis in dogs and humans in Bucaramanga, Colombia
}

M.Victoria Esteban-Mendoza

Universidad Cooperativa de Colombia

Víctor Arcila-Quiceno

Universidad Cooperativa de Colombia

Javier Hernando Albarracín-Navas

Universidad Cooperativa de Colombia

Isabel Hernández

University of Salamanca

María Camila Flechas-Alarcón N

Research Group from Higuera Escalante Clinical Laboratory and Blood Bank

Rodrigo Morchón ( $\sim$ rmorgar@usal.es )

University of Salamanca https://orcid.org/0000-0003-2699-1482

\section{Research}

Keywords: Dirofilaria immitis , dog, heartworm, human dirofilariasis, prevalence, seroepidemiology, Wolbachia pipientis

Posted Date: February 25th, 2020

DOI: https://doi.org/10.21203/rs.2.19256/v2

License: (c) (i) This work is licensed under a Creative Commons Attribution 4.0 International License. Read Full License 


\section{Abstract}

Background: The cardiopulmonary dirofilariasis caused by Dirofilaria immitis, is a vector-born infection, which can be transmitted to humans. The main host are both domestic and wild canids. It mainly occurs in tropical and subtropical climates, temperature and humidity are the main factors that favor the presence and proliferation of Culicidae mosquitoes. There are few reports of this disease in dogs and humans in Colombia, a region with favorable climatic conditions for the development of this disease. Therefore, this research aimed to study its current prevalence in dogs and the risk of human exposure to the disease in Bucaramanga, one of the most populated areas in Colombia located at the center of the country. Furthermore, its demographic and environmental characteristics could be useful as a study model for other similar locations and neighboring countries.

Method: Serum samples from 351 dogs and 506 humans from the Bucaramanga metropolitan area were analyzed. All dog samples were tested with a commercial immunochromatographic test kit to detect the presence of circulating antigens of D. immitis. Human samples were analyzed using a non-commercial ELISA test kit to detect IgG against the somatic antigens of adult D. immitis and Wolbachia . Positive results were further confirmed using a Western blot analysis.

Results: Dirofilaria immitis prevalence was $10.82 \%(95 \% \mathrm{Cl})$ in dogs and $5.12 \%(95 \% \mathrm{Cl})$ in microfilaremic dogs. Seroprevalence in humans was $6.71 \%(95 \% \mathrm{Cl})$ and was significantly higher in individuals aged $16-34$ years and in women than in men.

Conclusions: This study describes seropositivity to D. immitis for the first time in a Colombian human population located in the same area as that of dogs infected with D. immitis, which represents a potential threat to public health. In humans, age and sex can be considered risk factors for exposure to D. immitis .

\section{Background}

Cardiopulmonary dirofilariasis, caused by Dirofilaria immitis, is a vector-borne disease that occurs worldwide, and its main hosts are both domestic and wild canines and felines [1]. Different species of mosquitoes, such as the gender Culex spp., Aedes spp., and Anopheles spp., are involved in the transmission of this parasite. These species represent a constant risk of infection because they feed on both animal and human hosts [2]. Seroprevalence studies have been conducted in regions where infected dogs have been found, which indicated previous contact with the parasite and cases with pulmonary nodules. For this reason, dirofilariasis is considered an emerging public health problem because of its zoonotic potential $[3,4]$.

Cardiopulmonary dirofilariasis is a chronic, progressive, and life-threatening disease. Adult worms are lodged in the pulmonary artery and the right ventricle of a dog's heart. Female mosquitoes ingest the microfilariae, inside which they make two successive molts until stage-3, then the stage-3 larvae are inoculated into the definitive host during the next blood draw [2]. In humans, immature worms are embolized in the pulmonary micro arteries, leading to the formation of benign lung nodules (pulmonary dirofilariasis), most cases of which are asymptomatic [1,2]. Moreover, $D$. immitis harbors endosymbiotic bacteria of the genus Wolbachia, which participate in the parasite's molting and embryogenesis and play a key role in the immune and inflammatory response to the disease $[5,6]$.

Dirofilaria immitis is primarily located in tropical and subtropical climates and depends mainly on environmental factors, including temperature and humidity, in addition to human behavior such as installation of irrigation systems, taking pets on trips, and new urban developments, that favor the presence and proliferation of its transmission vectors. However, the number of reports in areas with cooler climates has increased, which indicates that the disease is expanding $[1,2,7,8]$. 
The South American continent is one of the most biodiverse areas on the planet, with a combination of factors such as intensification of agricultural practices, landscape modification, poor ecosystem protection, and potentially unstable economies, which lead to the spreading of the disease and its vectors [9]. On this continent, the disease has only been reported in Argentina, Colombia, Peru, and Brazil, with few studies in domestic dogs where sporadic cases of pulmonary dirofilariasis have been described $[1,10,11,12]$. The disease has been reported in dogs from different areas of Colombia, even in high-altitude areas with cold weather, with mean prevalence values of $0.91 \%-16.12 \%$ according to different methodologies [10,13]. Only one case of human pulmonary dirofilariasis has been described [14], and two seroepidemiological studies were conducted in an area within the Colombian Amazon where infected dogs were also found $[15,16]$.

The purpose of this investigation was to determine the presence of $D$. immitis in dogs and their possible contact with the human population in the metropolitan area of Bucaramanga, Colombia.

\section{Methods}

\section{Sampling area}

The metropolitan area of Bucaramanga, which belongs to the capital city of the Department of Santander in Colombia, includes the municipalities of Bucaramanga, Floridablanca, Piedecuesta, and Girón (Figure 1), located near the capital of Colombia, Bogotá. It extends to an area of $1,479 \mathrm{~km}^{2}$, and the municipal area occupies $165 \mathrm{~km}^{2}$; it is located at 959 $\mathrm{m}$ above sea level. It includes two sectors of different geographical conformations: one formed by a plateau and the other by a valley. Its climate is tropical, with a mean annual temperature of $23.4{ }^{\circ} \mathrm{C}$ and significant precipitation levels with an approximate mean of 1,159 $\mathrm{mm}$ [17]. It has an estimated population of 1.2 million people, and there are 32,000 censused dogs in the city of Bucaramanga alone. In addition, there are numerous uncensored vagrant dogs throughout this area [18].

\section{Samples used}

This study included samples from 351 dogs and 506 humans collected during the months of February-June 2018. All data is collected in Table 1. The dog and human samples were collected by members of the veterinary staff of different clinics and associations as well as the Higuera Escalante Laboratory's health care staff, respectively. For the canine population, signed informed consent from the owners was considered as an inclusion criterion. Variables considered for the analysis were age, gender, municipality of residence, socioeconomic status, and whether they lived inside or outside of the house. For the human population, being of legal age and signing the informed consent forms were the inclusion criteria. Variables for the analysis were age, gender, municipality of residence, socioeconomic status, living with pets, type of pet (dog or other), and presence of water sources at $<200$ meters. Confidentiality of patient information was always maintained, and all study participants gave their written consent. Socio-economic stratification was carried out taking six strata: The hierarchical socioeconomic differences were: misery (1), poverty (2), poverty with some economic resource (3), middle class (4), upper middle class (5) to upper class (6) [19].

\section{Immunological tests}

Dogs and human blood samples were collected in $3 \mathrm{~mL}$ tubes and centrifuged. The resulting serum was stored at -20 ${ }^{\circ} \mathrm{C}$ until further processing. Blood samples were also collected with EDTA for the study of microfilaremia in dogs. Dog 
serum samples were tested for the presence of $D$. immitis antigens using a commercial immunochromatographic test kit (Uranotest Dirofilaria ${ }^{\circledR}$, Urano Vet SL, Barcelona, Spain; sensitivity: $94,4 \%$, specificity: $100 \%$ ) according to the manufacturer's instructions. Microfilaria were sought in blood samples with EDTA by applying the Knott technique [20]. Human samples were analyzed using a non-commercial ELISA test kit to detect the specific responses of anti-D. immitis and anti-Wolbachia IgG antibodies with some modifications $[4,7,21,22]$. D. immitis adult worm extract (DiSA) and 1:100 serum dilutions were used to detect the presence of anti-D. immitis IgG antibodies. A recombinant form of the Wolbachia Surface Protein (rWSP) and 1:40 serum dilutions were used to detect the presence of anti-Wolbachia IgG antibodies. Goat anti-human IgG $(\mathrm{H}+\mathrm{L})$ conjugated to horseradish peroxidase (Sigma-Aldrich, Spain) was used at a 1:4000 dilutions in both cases. Optical densities (OD) were measured at $492 \mathrm{~nm}$ with an Easy Reader (Bio-Rad laboratories, USA). The cut-off point (OD $=0.8$ for DiSA and 0.5 for rWSP) was established by calculating the mean value +3 standard deviations (3SD) of 30 serum samples obtained from dogs and clinically healthy humans (negative controls) who belonged to an area free of $D$. immitis. Human sera were considered positive when both non-commercial

ELISAs were positive for the same serum sample. These results were additionally confirmed using Western blot analysis performed according to a previously described methodology $[23,24]$. Both antigenic extracts were subjected to SDSPAGE in $12 \%$ gels under reduced conditions, and proteins were transferred onto nitrocellulose. Human sera were analyzed at a 1:40 dilution and anti-conjugates at a 1:500 dilutions.

\section{Geospatial analysis}

A geospatial analysis was performed on the population of dogs and humans from the metropolitan area of Bucaramanga through a spatial overlay of positive cases using the SatScan software v.9.6. and the Bernoulli's model with a 95\% significance level (999 replications with $p<0.05$ ) based on the Monte Carlo statistical significance test. Further, we established clusters, which are areas with a relative risk of infection in dogs and humans, with a maximum size of $50 \%$ of the exposed population, based on population census and positive cases. Clusters were imported into the QGIS software (3.8.0 version) to be visualized on the study area map.

\section{Statistical analysis}

Data was analyzed using SPSS 20.0 software for Windows (SPSS Inc./IBM, Chicago, IL, USA). This is a descriptive study with a univariate analysis for the determination of frequencies and a bivariate analysis through chi-square and OR estimation, based on which a statistical analysis was performed for the determination of the association between variables. In all cases, the level of significance was established with $p<0.05$.

\section{Results}

Mean prevalence of $D$. immitis was $10.82 \%$ (38/351) in dogs and 5.12\% (18/351) in microfilaremic dogs. All prevalence and microfilaremia obtained by gender, age, municipality (Bucaramanga, Floridablanca, Girón, and Piedecuesta), breed, socioeconomic status and place of permanence are collected in Table 1. No statistically significant differences were observed between the variables: gender, age, municipalities, breeds, socioeconomic status, and place of permanence (inand -outdoors).

Mean seroprevalence in humans was $6.71 \%$ (34/506). All seroprevalence obtained by gender, age, municipality (Bucaramanga, Floridablanca, Girón, and Piedecuesta), socioeconomic status and place of permanence are collected in Table 2. All samples positive for Western blot analysis are shown in Figure 3. 
In the spatial exploration of dogs positive for D. immitis within the study area (Figure 3), no significant clusters were found. However, 4 significant clusters were detected taking into consideration the magnitude and distribution: one for positive dogs and 3 for seropositive humans $(p<0.01)$.

\section{Discussion}

In this study, we analyzed the presence of $D$. immitis in dogs and humans in the metropolitan area of Bucaramanga, Colombia, analyzing the presence of circulating antigens of $D$. immitis within the canine population, and the response of anti-D. immitis and anti-Wolbachia IgG antibodies in the human population as a study model for other places in Latin America.

The prevalence in Bucaramanga, Colombia, in dogs was $10.82 \%$, being the first study of this disease in this area. Bucaramanga is surrounded by vegetation and is characterized by an average annual temperature of $24{ }^{\circ} \mathrm{C}$, high humidity levels, several gullies in its proximity or even in the central areas that accumulate water in the rainy season, and the presence of two rivers (Oro and Surata in the areas of Girón and Bucaramanga, respectively). In addition, there are vector species described in the same area, such as Aedes aegypi, and others that could help to transmit the disease $[10,25]$. These conditions could promote breeding of these mosquitoes and disease transmission in said areas. Furthermore, prevalence in microfilaremic dogs was $5.12 \%$, which was heterogeneous. This situation is similar to that observed in other endemic areas where the disease has been reported $(2,4,7,8,10,26,27,28]$.

Regarding human infections, mean seroprevalence was $6.71 \%$, being the first time that a seroprevalence study was carried out in Latin America. The highest prevalence was $11.7 \%$ in Piedecuesta, followed by $6.9 \%$ in Bucaramanga, where prevalence in dogs reached similar values (12.5\% and $7.6 \%$, respectively); moreover, we observed slightly lower seroprevalence values of 5.7 in Floridablanca and 3.1\% in Girón. where the prevalence observed in dogs was 13.7\% and $12.9 \%$, respectively.

The occurrence of dirofilariasis in humans depends mainly on the presence of infected dogs and vectors for transmission within a given area. At the same time, other factors, such as increase in temperature and humidity owing to climate change; emergence of new disease-transmitting species; transportation of infected hosts; modification of the environment owing to human activities; agricultural practices and irrigation areas; deficiency and economic instability; and adverse meteorological events such as hurricanes or tropical rains in the area, affect the development of the disease. $[1,4,29]$. Further, it is important to note that although it is a vector-borne disease, not all L3 that come into contact with the host develop into adults, neither in dogs nor in wild hosts [9]. Most of the information regarding humans comes from clinical cases and retrospective reviews. In these cases, there is only data from the affected population that showed some type of clinical manifestation, excluding the infected population that does not have symptoms related to the disease or any clinical manifestation, making its study even more difficult. Seroepidemiological studies show the complementary part of the problem because they detect contact with the parasite by analyzing the anti-Dirofilaria and anti-Wolbachia immune response and are excellent tools to analyze the risk of infection among the human population residing in an endemic area $(1,4,7,22,26,27,28]$.

In Colombia, there is only one clinical case of a patient from whom an adult worm identified as Dirofilaria $s p$. was extracted from the lung [14], and there are two studies that warn of the existence of human infections caused by $D$. immitis in communities from the Colombian Amazon where infected dogs have been found $[15,16]$.

Data points related to the geographical location of the samples, and humans with positive serology have been reported in the same location as infected dogs. In addition, there are spatial clusters in these areas with a relative risk of $<1$ for humans, suggesting a positive association between the variables studied and a higher frequency of contact with the 
parasite. These data could suggest a relationship between the presence of $D$. immitis infected dogs and the seroprevalence obtained in humans. This is similar to what occurs in other European areas such as Spain, Portugal (6.1\%), Romania and Moldova (10.9\%), and Russia (0.63-4.3\%), where the risk of infection among humans has been studied $[1,4,7,8,26,27,28]$.

Regarding the variables evaluated, we observed that age can be a risk factor. In our study, the population with the highest seropositivity was that from the age group of 51-65 years. This result is similar to other studies that report that the risk of infection increases with age $[4,7,8,26,27,28]$.

Furthermore, not only did this study allow us to address the problem from a biological point of view but also from a socioeconomic point of view in case of humans. The highest seroprevalence was observed in stratum 1, where sanitary hygiene conditions are not adequate (20\%), followed by stratum 2 (8.3\%), stratum $3(5.7 \%)$, and stratum 4 (4.1\%). Seropositive individuals were not detected in the last two strata where the sanitary hygiene level is optimal.

Socioeconomic status has been associated with mortality and the use of health services, which indicates that a lower income reduces the application of prophylactic and preventive measures to vectors and canines that live with humans [30]. Environmental sanitation elements, such as water; sewage, garbage, and waste disposal; sanitary landfills; and garbage treatment, influence the prevalence of parasitosis. This data allows us to associate the lack of sanitary hygiene with the development of dirofilariasis, which may become a socially-determinant public health factor, as in the case of other vector-borne diseases in Colombia such as malaria, leishmaniosis and Chagas disease [9,31,32].

\section{Conclusions}

In conclusion, this study describes, for the first time, seropositivity to D. immitis and WSP in a human population in Colombia, specifically in one of the most populated areas of the country, the metropolitan area of Bucaramanga, with a high presence of dogs infected by $D$. immitis, which are a potential threat to public health. The corresponding authorities should take measures to monitor and control this emerging zoonotic disease to reduce prevalence in canines, while including human pulmonary dirofilariasis in the differential diagnosis of pulmonary nodules. However, it is necessary to perform further studies in Colombia regarding vectors and reservoirs of infection using a larger sample size, as well as epidemiological studies in humans to clarify the risk of this infection.

\section{Abbreviations}

3SD: 3 standard deviations; Cl: confidence interval; DiSA: D. immitis adult worm extract; EDTA: ethylenediaminetetraacetic acid; ELISA: enzyme-linked immunosorbent assay: IgG: Immunoglobulin G: rWSP: recombinant Wolbachia surface protein; OD: optical densities; SDS-PAGE; sodium dodecyl sulfatepolyacrylamide gel electrophoresis.

\section{Declarations}

\section{Ethics approval and consent to participate}

The sampling process complied with the Helsinki code of ethics and animal welfare and was approved under resolution Nº40-2019 by the Ethics Committee of Universidad Cooperativa de Colombia.

\section{Consent for publication}


Not applicable.

\section{Availability of data and materials}

The datasets supporting the conclusions of this article are included within the article.

\section{Competing interests}

The authors declare that they have no competing interests.

\section{Funding}

This study has been supported by Universidad Cooperativa de Colombia (INV2213) and Agencia de Desarrollo Económico de Castilla y León, Spain (cofinanced with FEDER funds).

\section{Authors' contributions}

MVEM, RM and VAQ designed the study and wrote the manuscript. LAN, IH and CFA performed the fieldwork and collected the data. MVEM, RM and VAQ participated in the discussion of the results and corrected the manuscript. All authors read and approved the final manuscript.

\section{Acknowledgments}

We would like to thank the staff of the Higuera Escalante Blood Bank and veterinarians from the companion animals' clinic of Universidad Cooperativa de Colombia, Biovet veterinary clinical diagnosis.

\section{Author details}

${ }^{1}$ GRICA Group, Universidad Cooperativa de Colombia, School of Veterinary Medicine and Zootechnics, Master's in Animal Health and Production, UCC, Calle 30 No. 33-51, Bucaramanga, Colombia. ${ }^{2}$ Group of Animal and Human Dirofilariasis, Parasitology Area, Faculty of Pharmacy, University of Salamanca, Campus Miguel Unamuno s/n, 37007, Salamanca, Spain. ${ }^{3}$ Research Group from Higuera Escalante Clinical Laboratory and Blood Bank, Bucaramanga, Colombia

\section{References}

[1] Simón F, Siles-Lucas M, Morchón R, González-Miguel J, Mellado I, Carretón E, Montoya-Alonso JA. Human and animal dirofilariasis: the emergence of a zoonotic mosaic. Clin Microbiol Rev. 2012;25(3):507-44. 
[2] Morchón R, Carretón E, González-Miguel J, Mellado-Hernández I. Heartworm disease (Dirofilaria immitis) and their vectors in Europe - new distribution trends. Front Physiol. 2012;3:196.

[3] Montoya-Alonso JA, Carretón E, Morchón R, Silveira-Viera L, Falcón Y, Simón F. The impact of the climate on the epidemiology of Dirofilaria immitis in the pet population of the Canary Islands. Vet Parasitol. 2016;216:66-71.

[4] Fontes-Sousa AP, Silvestre-Ferreira AC, Carretón E, Esteves-Guimarães J, Maia-Rocha C, Oliveira P, Lobo L, Morchón R, Araújo F, Simón F, Montoya-Alonso JA. Exposure of humans to the zoonotic nematode Dirofilaria immitis in Northern Portugal. Epidemiol Infect. 2019;147, e282, 1-5.

[5] Simón F., Kramer LH, Román A., Blasini W., Morchón R., Marcos-Atxutegi C., Grandi G., Genchi C. Immunopathology of Dirofilaria immitis Infection. Vet Res Commun. 2007;31:161-71.

[6] Genchi C, Kramer LH, Sassera D, Bandi C. Wolbachia and its implications for the immunopathology of filariasis. Endocr Metab Immune Disord Drug Targets. 2012;12(1):53-6.

[7] Ciuca L, Simòn F, Rinaldi L, Kramer L, Genchi M, Cringoli G, Acatrinei D, Miron L, Morchon R. Seroepidemiological survey of human exposure to Dirofilaria spp. in Romania and Moldova. Acta Trop. 2018;187:169-74.

[8] Kartashev V, Afonin A, González-Miguel J, Sepúlveda R, Simón L, Morchón R, Simón F. Regional warming and emerging vector-borne zoonotic dirofilariasis in the Russian Federation, Ukraine, and other post-Soviet states from 1981 to 2011 and projection by 2030. Biomed Res Int. 2014;2014:858936.

[9] Maggi RG, Krämer F. A review on the occurrence of companion vector - borne diseases in pet animals in Latin America. Parasit Vectors. 2019;12(1):145.

[10] Labarthe N, Guerrero J. Epidemiology of heartworm: What is happening in South America and Mexico? Vet Parasitol. 2005;133:149-56.

[11] Dantas-Torres F, Otranto D. Dirofilariasis in the Americas: a more virulent Dirofilaria immitis? Parasit Vectors [Internet]. 2013;6(1):288.

[12] de Argôlo EGG, Reis T, Fontes DAT, Gonçalves EC, Giese EG, Melo FTV, Dos Santos JN, Furtado AP. Canine filariasis in the Amazon: Species diversity and epidemiology of these emergent and neglected zoonoses. PLoS One. 2018;13(7):e0200419.

[13] McCown ME, Monterroso VH, Cardona W. Surveillance for Ehrlichia canis, Anaplasma phagocytophilum, Borrelia burgdorferi, and Dirofilaria immitis in Dogs From Three Cities in Colombia. J Spec Oper Med. 2014;14(1):86-90.

[14] Beaver PC, Orihel TC LG. Pulmonary dirofilariasis: restudy of worms reported gravid. Am J Trop Med Hyg [Internet]. 1990;43(2):9-167.

[15] Vieira C., Montoya M., Agudelo S., Simón F. Human antibody response to a 56-kDa purified excretory/secretory product of Dirofilaria immitis. Trop Med Int Heal. 2000;5(12):855-9.

[16] Vieira C, Vélez ID, Montoya MN, Agudelo S, Alvarez MI, Genchi C, Simón F. Dirofilaria immitis in Tikuna Indians and their dogs in the Colombian Amazon. Ann Trop Med Parasitol. 1998;92(1):123-5.

[17] Climate-Data.org / AM OP / OpenStreetMap contributors. Clima Bucaramanga: Temperatura, Climograma y Tabla climática para Bucaramanga - Climate-Data.org [Internet]. [cited 2019 Jun 24]. Available from: https://es.climate- 
data.org/america-del-sur/colombia/santander/bucaramanga-5923/

[18] Albarracín Navas J, Cala FA. Primer censo canino y felino del área urbana del municipio de Bucaramanga. Rev Colom Cienc Pecua [Internet]. 2011.

[19] DANE. Clasificación socio-económica Colombia. 2019. [cited 2019 Dec 14]. Available from:

https://www.dane.gov.co/files/geoestadistica/Preguntas_frecuentes_estratificacion.pdf

[20] Acevedo RA, Theis JH, Kraus JF, Longhurst WM. Combination of filtration and histochemical stain for detection and differentiation of Dirofilaria immitis and Dipetalonema reconditum in the dog. Am J Vet Res. 1991;42:537-40.

[21] Simón F, Muro A, Cordero M, Martin J. A seroepidemiologic survey of human dirofilariosis in Western Spain. Trop Med Parasitol. 1991;42(2):106-8.

[22] Simón F, Prieto G, Morchón R, Bazzocchi C, Bandi C, Genchi C. Immunoglobulin G antibodies against the endosymbionts of filarial nematodes (Wolbachia) in patients with pulmonary dirofilariasis. Clin Diagn Lab Immunol. 2003;10(1):180-1.

[23] Perera L, Pérez-Arellano JL, Cordero M, Simón F, Muro A. Utility of antibodies against a 22 kD molecule of Dirofilaria immitis in the diagnosis of human pulmonary dirofilariasis. Trop Med Int Health. 1998;3(2):151-5.

[24] Santamaría B, Cordero M, Muro A, Simón F. Evaluation of Dirofilaria immitis excretory/secretory products for seroepidemiological studies on human dirofilariosis Parasite. 1995;2(3):269-73.

[25] Ruiz R, Gustavo A, Parra J, Duque JE. Oviposition dynamics of Aedes (Stegomyia) aegypti (Diptera: Culicidae), gonadotrophic state and coexistence with other culicidae in the metropolitan area of Bucaramanga. Rev Univ Ind Santander, Salud. 2018;50(4):308-9.

[26] Cabrera ED, Carretón E, Morchón R, Falcón-Cordón Y, Falcón-Cordón S, Simón F, Montoya-Alonso JA. The Canary Islands as a model of risk of pulmonary dirofilariasis in a hyperendemic area. Parasitol Res. 2018;117(3):933-6.

[27] Montoya-Alonso JA, Mellado I, Carretón E, Cabrera-Pedrero ED, Morchón R, Simón F. Canine dirofilariasis caused by Dirofilaria immitis is a risk factor for the human population on the island of Gran Canaria, Canary Islands, Spain.

Parasitol Res [Internet]. 2010;107(5):1265-9.

[28] Montoya-Alonso JA, Carretón E, Corbera JA, Juste MC, Mellado I, Morchón R, Simón F. Current prevalence of Dirofilaria immitis in dogs, cats and humans from the island of Gran Canaria, Spain. Vet Parasitol. 2011;176(4):291-4.

[29] AHS, 2019. [cited 2019 Dec 14]. Available from: [https://www.heartwormsociety.org/]

[30] Agudelo C, Villareal E, Cáceres E, López C, Eljach J, Ramírez N, Hernández C, Corredor A. Human and dogs Toxocara canis infection in a poor neighborhood in Bogota. Mem Inst Oswaldo Cruz. 1990; 85(1):75-8.

[31] Caraballo L, Coronado S. 2018. Parasite allergens. Mol Immunol.100:113-9.

[32] Feachem RGA, Chen I, Akbari O, Bertozzi-Villa A, Bhatt S, Binka F, Boni MF, Buckee C, Dieleman J, Dondorp A, Eapen A, Sekhri Feachem N, Filler S, Gething P, Gosling R, Haakenstad A, Harvard K, Hatefi A, Jamison D, Jones KE, Karema C, Kamwi RN, Lal A, Larson E, Lees M, Lobo NF, Micah AE, Moonen B, Newby G, Ning X, Pate M, Quiñones M, Roh M, Rolfe B, Shanks D, Singh B, Staley K, Tulloch J, Wegbreit J, Woo HJ, Mpanju-Shumbusho W. Malaria eradication within a generation: ambitious, achievable, and necessary. Lancet. 2019;394(10203):1056-112. 
Tables

Table 1. Prevalence in dogs in the Bucaramanga Metropolitan area in terms of gender, age, municipality, socioeconomic status, and their place of permanence.

\begin{tabular}{|c|c|c|c|c|c|c|c|c|c|}
\hline Variable & $\begin{array}{c}\mathrm{n}^{\circ} \\
\text { samples } \\
(\%)\end{array}$ & $\begin{array}{c}\mathrm{n}^{0}+D_{.} \\
\text {immitis }\end{array}$ & Prevalence & $\mathrm{Cl} 95 \%$ & OR & $\begin{array}{c}\mathrm{n}^{0} \\
\mathrm{mf} \\
\text { dogs }\end{array}$ & Prevalence & $\mathrm{Cl} 95 \%$ & OR \\
\hline \multicolumn{10}{|l|}{ Gender } \\
\hline Male & $\begin{array}{c}132 \\
(3761 \%)\end{array}$ & 14 & $10.6 \%$ & $.0474-.1511$ & 0.977 & 7 & $5 \%$ & $.0144-0,925$ & 1.036 \\
\hline Female & $\begin{array}{c}219 \\
(62.39 \%)\end{array}$ & 24 & $10.95 \%$ & $.0679-.1513$ & 1.014 & 11 & $5 \%$ & $.0211-.0794$ & 0.978 \\
\hline \multicolumn{10}{|l|}{ Age } \\
\hline$<1$ & $31(18 \%)$ & 2 & $6.45 \%$ & $-.0271-.1561$ & 0.974 & 0 & $0.00 \%$ & $.000-.000$ & 0 \\
\hline $1-3.9$ & $\begin{array}{c}109 \\
(19 \%)\end{array}$ & 11 & $10.09 \%$ & $.0435-.1584$ & 1.051 & 5 & $4.59 \%$ & $.0060-.0858$ & 0.948 \\
\hline $4-6.9$ & $\begin{array}{c}119 \\
(17 \%)\end{array}$ & 11 & $9.24 \%$ & $.0338-.1357$ & 0.722 & 7 & $5.88 \%$ & $.0106-.0911$ & 1.047 \\
\hline $7-10.9$ & $67(39 \%)$ & 12 & $17.91 \%$ & $.0849-.2733$ & 1.216 & 5 & $7.46 \%$ & $-.0061-.0956$ & 0.569 \\
\hline $11-15$ & $25(16 \%)$ & 2 & $8.00 \%$ & $-.0343-.1943$ & 0.484 & 1 & $4.00 \%$ & $.0056-.3144$ & 2.313 \\
\hline \multicolumn{10}{|l|}{ Municipalities } \\
\hline Bucaramanga & $\begin{array}{c}144 \\
(41 \%)\end{array}$ & 11 & $7.6 \%$ & $.0276-.1122$ & 0.854 & 2 & $1 \%$ & $-.0055-.0335$ & 0.802 \\
\hline Floridablanca & $\begin{array}{c}73 \\
(20.8 \%)\end{array}$ & 10 & $13.7 \%$ & $.0562-.2178$ & 1.303 & 2 & $3 \%$ & $-.0110-.0657$ & 1.405 \\
\hline Girón & $\begin{array}{c}70 \\
(19.9 \%)\end{array}$ & 9 & $12.9 \%$ & $.0482-.2090$ & 0.455 & 8 & $11 \%$ & .0379-.1907 & 0.759 \\
\hline Piedecuesta & $\begin{array}{c}64 \\
(18.2 \%) \\
\end{array}$ & 8 & $12.5 \%$ & $.0417-.2083$ & 1.664 & 6 & $9 \%$ & $.0204-01671$ & 1.269 \\
\hline \multicolumn{10}{|c|}{ Socioeconomic level } \\
\hline Stratum 1 & $\begin{array}{c}139 \\
(39.60 \%)\end{array}$ & 16 & $11.51 \%$ & $.0614-.1688$ & 1.029 & 12 & $9 \%$ & $.0391-.1336$ & 1.337 \\
\hline Stratum 2 & $\begin{array}{c}57 \\
(16.23 \%)\end{array}$ & 6 & $10.5 \%$ & $.0231-.1874$ & 0.93 & 1 & $2 \%$ & $-.0176-.0527$ & 0.251 \\
\hline Stratum 3 & $\begin{array}{c}79 \\
(22.50 \%)\end{array}$ & 10 & $12,60 \%$ & $.0516-.2015$ & 1.25 & 2 & $3 \%$ & $-.0101-.0607$ & 0.378 \\
\hline Stratum 4 & 75 & 6 & $8.00 \%$ & $.0090-.1261$ & 0.75 & 3 & $4 \%$ & $-.0066-.0865$ & 1.242 \\
\hline Stratum 5 & $\begin{array}{c}1 \\
(028 \%)\end{array}$ & 0 & $0.00 \%$ & $.000-.000$ & 0 & 0 & $0 \%$ & $.000-.000$ & 0 \\
\hline Stratum 6 & $\begin{array}{c}(0.28 \%) \\
0 \\
(0.00 \%)\end{array}$ & 0 & $0.00 \%$ & $.000-.000$ & 0 & 0 & $0 \%$ & $.000-.000$ & 0 \\
\hline \multicolumn{10}{|c|}{ Place of permanence } \\
\hline Indoors & $\begin{array}{c}187 \\
(53.27 \%)\end{array}$ & 17 & $9.09 \%$ & $.0493-.1325$ & 0.824 & 7 & $4 \%$ & $.0100-.0649$ & 0.717 \\
\hline Outdoors & $\begin{array}{c}164 \\
(46,72 \%) \\
\end{array}$ & 21 & $12.8 \%$ & $.0718-.1736$ & 1.21 & 11 & $7 \%$ & $.0286-.1064$ & 1.335 \\
\hline TOTAL & 351 & 38 & $10.82 \%$ & & & 18 & $5.12 \%$ & & \\
\hline
\end{tabular}

Table 2. Seroprevalence of human dirofilariasis in the metropolitan area of Bucaramanga, considering seropositivity is defined by the simultaneous positivity of anti-D. immitis and anti-rWSP antibody response. 


\begin{tabular}{|c|c|c|c|c|c|}
\hline \multirow{2}{*}{\multicolumn{6}{|c|}{ Gender }} \\
\hline & & & & & \\
\hline Male & 159 & 9 & $5.7 \%$ & $.3192-.8808$ & 0.773 \\
\hline Female & 347 & 25 & $7.2 \%$ & $.3939-6930$ & 1.294 \\
\hline \multicolumn{6}{|l|}{ Age } \\
\hline $18-35.9$ & 294 & 17 & $5.8 \%$ & $.2695-.6905$ & 0.465 \\
\hline $36-50.9$ & 118 & 10 & $8.5 \%$ & $.2248-.7752$ & 1.509 \\
\hline $51-65.9$ & 73 & 7 & $9.6 \%$ & $.2823-1.0510$ & 1.057 \\
\hline $66-90$ & 21 & 0 & $0.0 \%$ & $-5.8531-6.8531$ & 0.941 \\
\hline
\end{tabular}

Municipalities

\begin{tabular}{l|c|c|c|c|c}
\hline Bucaramanga & 189 & 13 & $6.9 \%$ & $.4540-.9144$ & 1.098 \\
Floridablanca & 176 & 10 & $5.7 \%$ & $.2286-.6805$ & 0.896 \\
Girón & 64 & 2 & $3.1 \%$ & $-.4187-1.4187$ & 0.381 \\
Piedecuesta & 77 & 9 & $11.7 \%$ & $.3192-.8808$ & 1.564 \\
\hline
\end{tabular}

Socioeconomic status

\begin{tabular}{l|c|c|c|c|c}
\cline { 2 - 5 } Stratum 1 & 30 & 6 & $20.0 \%$ & $.3016-.8010$ & 2.149 \\
Stratum 2 & 144 & 12 & $8.3 \%$ & $.3406-.8023$ & 2.03 \\
Stratum 3 & 193 & 11 & $5.7 \%$ & $.2093-.6055$ & 1.126 \\
Stratum 4 & 121 & 5 & $4.1 \%$ & $.2630-1.1656$ & 0.803 \\
Stratum 5 & 16 & 0 & $0.0 \%$ & $.000-.000$ & 0 \\
Stratum 6 & 2 & 0 & $0.0 \%$ & $.000-.000$ & 0 \\
\hline
\end{tabular}

Water sources located at $<200$ meters from the house

\begin{tabular}{l|l|l|l|l|l} 
Yes & 232 & 15 & $6.5 \%$ & $.3734-.7804$ & 0.936 \\
No & 274 & 19 & $6.9 \%$ & $.3692-.7165$ & 1.069 \\
\hline
\end{tabular}

Living with pets or not

\begin{tabular}{l|c|c|c|c|c}
\cline { 2 - 5 } Yes & 377 & 28 & $7.4 \%$ & $.4622-.7552$ & 1.645 \\
No & 129 & 6 & $4.7 \%$ & $.1192-.6808$ & 0.608 \\
Canines & 335 & 26 & $7.8 \%$ & $.3760-.7668$ & 0.58 \\
Other species & 171 & 8 & $4.7 \%$ & $.3889-.6808$ & 1.101 \\
\hline TOTAL & $\mathbf{5 0 6}$ & $\mathbf{3 4}$ & $\mathbf{6 . 7 1 \%}$ & &
\end{tabular}

\section{Figures}




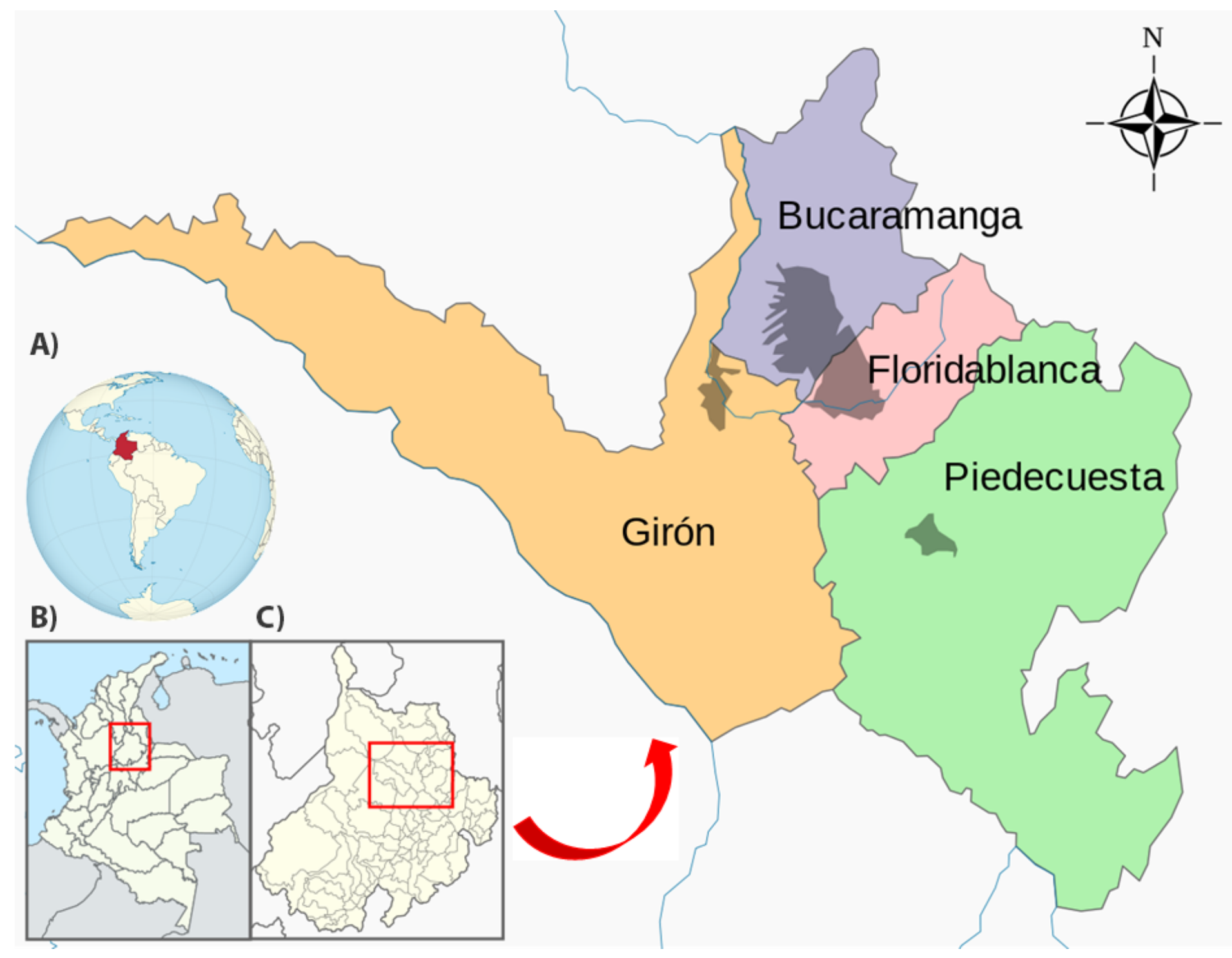

Figure 1

Location of the metropolitan area of Bucaramanga, Colombia. 


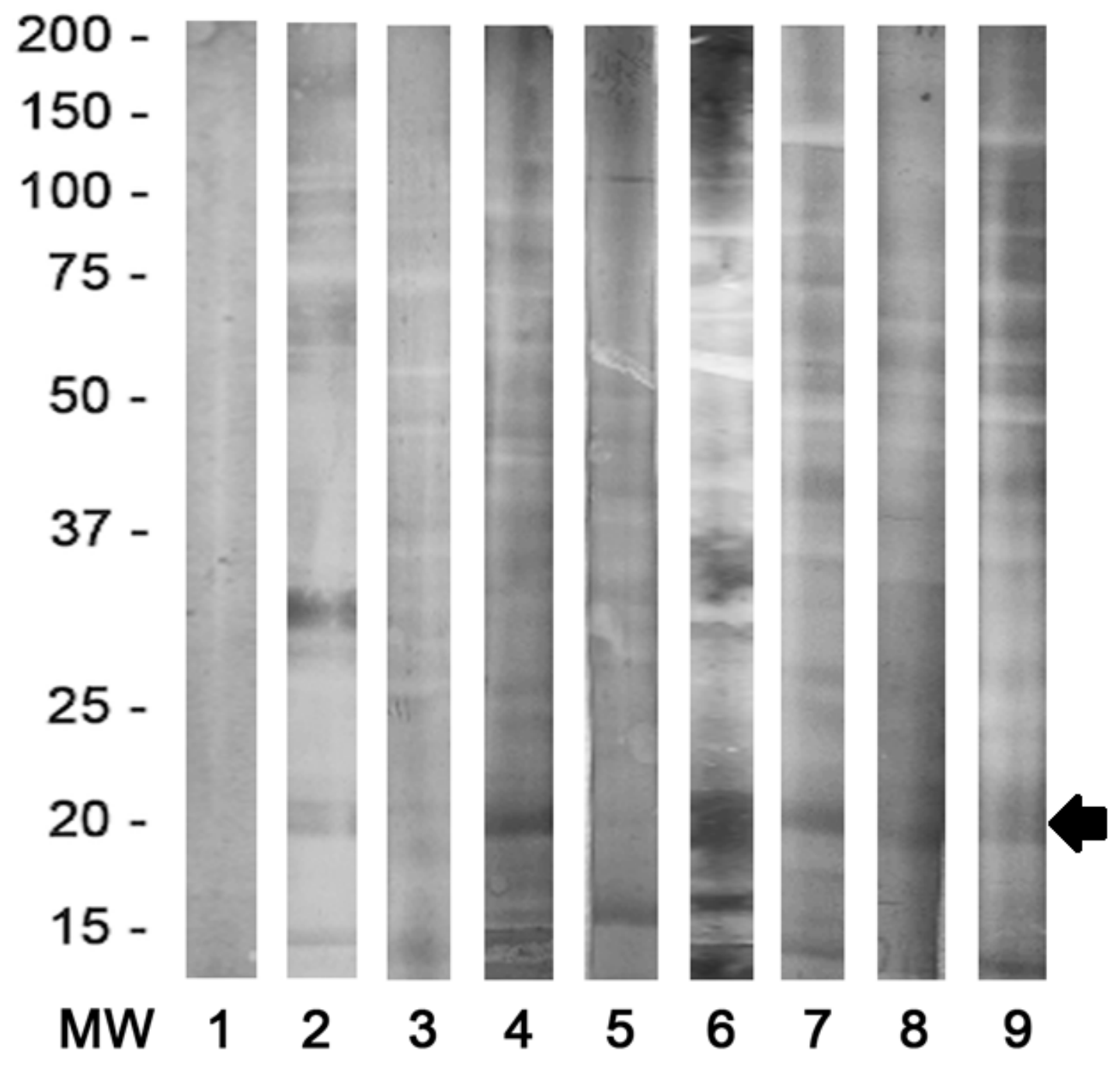

Figure 2

Representative immunoblot analysis of the human sera: Negative control (1) and Dirofilaria immitis-positive (2-9) specific bands between 17-22 kDa. 


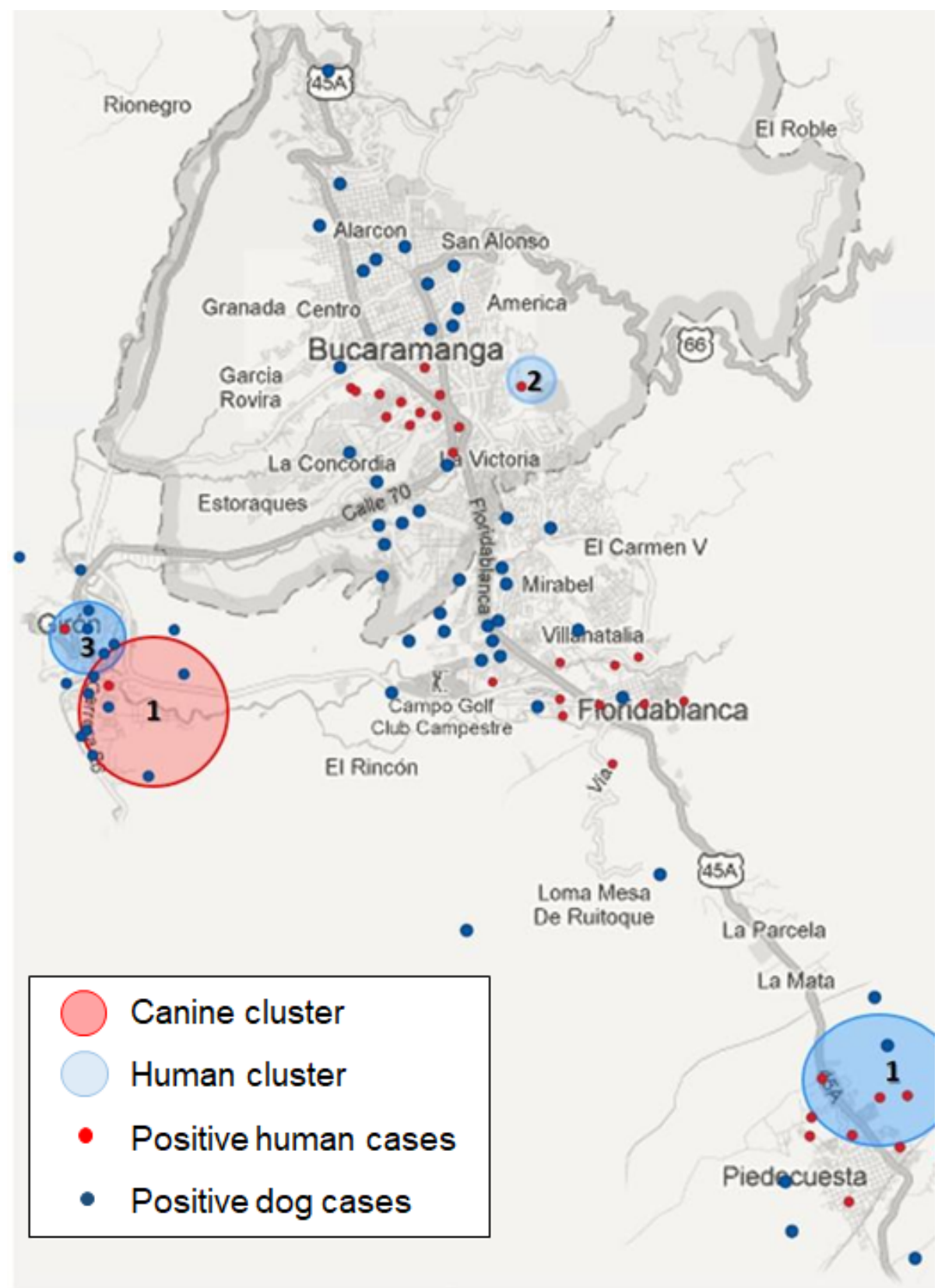

Figure 3

Geospatial exploration of dogs and humans positive for D. immitis in the metropolitan area of Bucaramanga imported into Qgis program (version 3.8.0).

\section{Supplementary Files}

This is a list of supplementary files associated with this preprint. Click to download.

- GraphicalAbstractNEW.tif 